\section{J. Slotboom \\ C. Kiefer \\ C. Brekenfeld \\ C. Ozdoba \\ L. Remonda \\ K. Nedeltchev \\ M. Arnold \\ H. Mattle \\ G. Schroth}

\title{
Locally induced hypothermia for treatment of acute ischaemic stroke: a physical feasibility study
}

Received: 1 February 2004

Accepted: 12 August 2004

Published online: 17 November 2004

(C) Springer-Verlag 2004

\author{
J. Slotboom $(\square) \cdot$ C. Kiefer \\ C. Brekenfeld · C. Ozdoba \\ L. Remonda $\cdot$ K. Nedeltchev $\cdot$ G. Schroth \\ Institute of Diagnostic and Interventional \\ Neuroradiology, University of Bern, \\ Inselspital, 3010 Berne, Switzerland \\ E-mail: johannes.slotboom@insel.ch \\ Tel.: + 41-31-6323691 \\ M. Arnold · H. Mattle \\ Department of Neurology, University \\ of Bern, Inselspital, Berne, Switzerland
}

\begin{abstract}
During the treatment of stroke by local intra-arterial thrombolysis (LIT) it is frequently possible to pass the blood clot with a microcatheter, allowing perfusion of brain tissue distally to the occlusion. This possibility allows for new early treatments of ischaemic brain tissue, even before the blood clot has been removed. One potential new approach to preserve brain tissue at risk may be locally induced endovascular hypothermia. Physical parameters such as the required micro-catheter input pressure, output velocity and flow rates, and a heat exchange model, applicable in the case of a micro-catheter placed within a guiding catheter, are presented. Also, a simple cerebral temperature model is derived that models the temperature response of the brain to the perfusion with coolant fluids. Based on this model, an expression has been derived for
\end{abstract}

the time needed to reach a certain cerebral target temperature. Experimental in vitro measurements are presented that confirm the usability of standard commercially available micro-catheters to induce local hypothermia of the brain. If applied in vivo, the model predicts a local cooling rate of ischaemic brain tissue of $300 \mathrm{~g}$ of approximately $1^{\circ} \mathrm{C}$ in $1 \mathrm{~min}$, which is up to a factor 30-times faster than the time-consuming systemic hypothermia via the skin. Systemic body temperature is only minimally affected by application of local hypothermia, thus avoiding many limitations and complications known in systemic hypothermia.

Keywords Hypothermia · Heat transfer $\cdot$ Brain $\cdot$ Stroke $\cdot$ Physical modelling $\cdot$ Local intra-arterial thrombolysis (LIT)

\section{Introduction}

It is commonly known that deep hypothermia dramatically reduces the demand for glucose and oxygen. For instance, in a study of 15 patients, suffering from accidental deep hypothermia with circulatory arrest of $15 \pm 19$ min, it was observed that none of the surviving patients suffered any brain lesions visible on MRI scans, or neurological or neuropsychological disorders [1]. Animal studies (e.g. [2]), as well as human studies [3, 4, 5, 6], have shown that induced hypothermia has a positive therapeutic effect in the treatment of stroke. Inducing hypothermia in patients suffering from stroke can be achieved by cooling the patient's whole body (systemic hypothermia) or by cooling the ischaemic area locally (local hypothermia). Both methods will be discussed.

Systemic hypothermia

There is a direct relationship between body temperature, body size, and metabolic rate. Gillooly et al. [7] showed 
that the metabolic rate is proportional to $M^{3 / 4} \exp \left(-E_{\mathrm{i}} /\right.$ $\left.k_{\mathrm{B}} T\right)$, in which $M$ is the body mass, $T$ the body temperature, $E_{\mathrm{i}}$ the average activation energy for metabolic reactions (in the range of $0.2-1.2 \mathrm{eV}$ ), and $k_{\mathrm{B}}$ is Boltzmann's constant. Under the assumption that the average enzyme-catalysed activation energy $\left\langle E_{\mathrm{i}}\right\rangle$ equals $0.6 \mathrm{eV}$, lowering the human body temperature by $1{ }^{\circ} \mathrm{C}$ results in an $8 \%$ lower metabolic rate. As a slowed metabolism has less need for oxygen and glucose [8], cooled ischaemic tissue is able to sustain an ischaemic/hypoxic period for a longer time.

Classical ways of cooling the body include the use of fluid-circulating cooling blankets, electric fans, rubbing patients with alcohol/water solutions and lowering ambient temperature. Very recent technological developments are special cooling devices that allow the induction of moderate hypothermia (body temperature of $34^{\circ} \mathrm{C}$ ) within an hour (e.g. Celsius Control System, Innercool Therapies, San Diego, Calif., USA, and the SetPoint Endovascular temperature therapy system, Radiant Medical, Redwood City, Calif., USA). Both systems make use of specially developed heat-exchange catheters that are placed in the inferior vena cava. Clinical tests have been carried out and are currently being performed with these new devices in multi-centre studies, investigating the influence of hypothermia therapy in myocardial infarction (COOL MI [9]) and investigating the effect of induced hypothermia in severe stroke due to middle cerebral artery occlusion (COOL AID [10]). As in the classic way of inducing hypothermia via the skin, these new endovascular cooling devices also induce whole-body hypothermia. The time to reach mild hypothermia of $32^{\circ}$ to $33^{\circ}$ body core temperature is reported to be, on average, $3.5 \mathrm{~h}$ with the classical methods, and roughly $1 \mathrm{~h}$ with the new endovascular devices.

\section{Local hypothermia}

There are several ways to induce local hypothermia in the brain. Cooling of the brain via the skull with the aid of a cooling helmet has been described very recently [11]. Due to the slow thermal conduction of heat from the brain to the helmet, it takes on average $3.4 \mathrm{~h}$ to cool the brain down to $34^{\circ} \mathrm{C}$, which is a considerably long time when compared with the therapeutic window. The method is also reported to reduce the systemic temperature to values lower that $36^{\circ} \mathrm{C}$ after $6.7 \mathrm{~h}$. Another way of cooling the brain locally was proposed by Noguchi et al. [12], who used cold saline solution to perfuse the subdural space in a rat study. The results presented are promising, but the drawback of this method is that the skull needs to be opened, which is a major disadvantage for clinical use in the case of stroke.

A third way to induce local hypothermia is by local intra-arterial perfusion with cold saline solution. Owing to the fact that the cold liquid is transported through the microvasculature, the heat exchange is most efficient, and cooling can be achieved very rapidly, as will be shown in this paper. During the review process of this paper, a study by Ding et al. [13] was published, showing the first results of a local endovascular cooling method, similar to that proposed in this paper, applied to rats after transient middle cerebral artery occlusion. Ding et al. showed that local endovascular induced hypothermia significantly reduced the infarct volume by $90 \%$ and improved the motor behaviour of rats significantly when compared with non-treated rats.

This paper deals with a physical feasibility study of whether it is possible to induce local hypothermia of the ischaemic brain area in human beings by the use of standard guiding catheters - and micro-catheters - which are used in the daily routine of interventional neuroradiology, especially the well-established stroke treatment by local intra-arterial thrombolysis (normally used for intra-arterial thrombolysis).

\section{Methods}

Local intra-arterial thrombolysis (LIT) using pro-urokinase has been found to improve the outcome of patients with acute M1 or M2 segment occlusions of the middle cerebral artery (MCA) (PROACT study [14]) when administered within $6 \mathrm{~h}$ [15]. In addition, several series showed that LIT could be safely and efficaciously applied in everyday practice in middle cerebral artery [16] or basilar artery occlusion [17]. From the methodological point of view, LIT is a safe, quick and easily performed neuro-radiological intervention: the tip of a five, up to an eight, French guiding catheter is placed in the vertebral or internal carotid artery by a transfemoral approach and a micro-catheter, mostly a FasTracker 18 (Boston Scientific), is navigated through this guiding catheter in front of (PROACT) or into the occluded intracranial blood vessel [17]. Figure 1a shows this situation schematically. During LIT, a thrombolytic agent supplied to the patient via a micro-catheter dissolves the occluding thrombus. Based on the experience of more than 300 patients treated with LIT in our university-based stroke unit [18], and corresponding with the well-known experiences of many other neuroradiological centres performing LIT, it frequently occurred that the tip of the micro-catheter could pass the site of occlusion (see Fig. 1b). This would allow an artificial perfusion of the devascularized brain located distally to the blood clot (Figs. 2, 3). The ability to perfuse the core and penumbra of brain infarction even before the thrombolytic agent has dissolved the thrombus allows for various additional new types of early and neuroprotective treatments of the ischaemic brain tissue. 


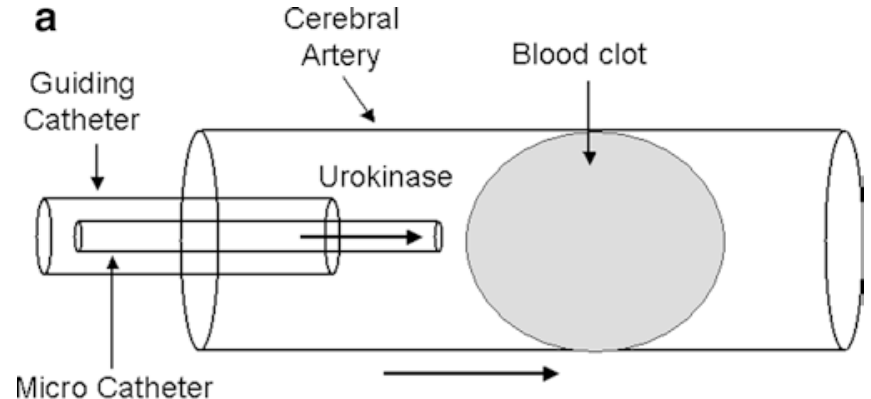

Blood Flow Direction

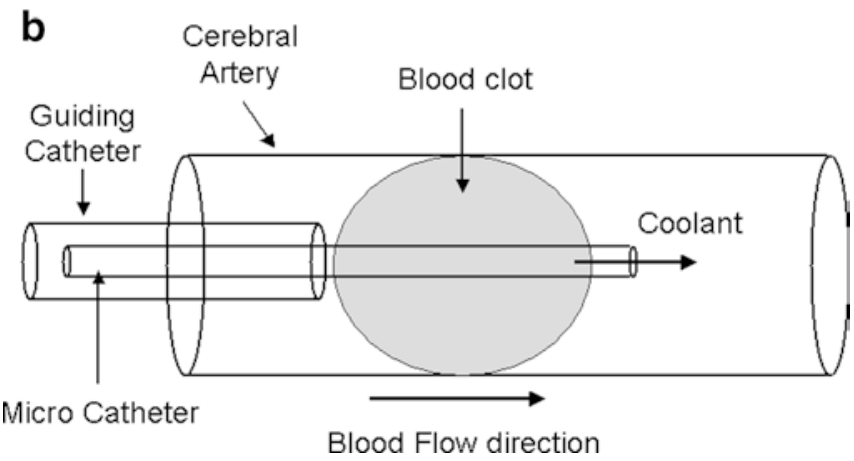

Fig. 1 a The end of the micro-catheter that releases the thrombolytic agent (e.g. urokinase) is positioned such that it is very close to the occluding blood clot. b Often it is possible to pass through the blood clot and/or between the clot and the wall of the vessel with the catheter allowing the reperfusion of infarcted tissue distally of the blood clot

The goal of the study presented here was to determine whether it is physically possible to induce local hypothermia via a micro-catheter in a human. To answer this question, a thermal model of the micro-catheter and a thermal model of the infarcted brain area that models the thermal response of the brain to cooling were developed. These models allow the calculation of the necessary amount of cooling fluid that has to be administered per time unit in order to reach a certain target brain temperature within a certain amount of time. The derived model also allows estimation of the worst-case systemic cooling effect on the body.

Owing to the theoretical nature of the subject dealt with in this paper, this section will describe, besides the methodological aspects of the study, theoretical aspects of the heat-exchange processes in the human body, several

Fig. 2a-c Angiography of a 56-year-old woman with acute left-sided hemiplegia. a Angiography of the right internal carotid artery demonstrates the occlusion of the proximal segment of the MCA. b The micro-catheter is navigated through the occlusion, which is confirmed by a gentle injection of contrast agent. c Revascularization of the MCA after intra-arterial thrombolysis (injection of one million units urokinase proximally, into, and distal of the site of occlusion)
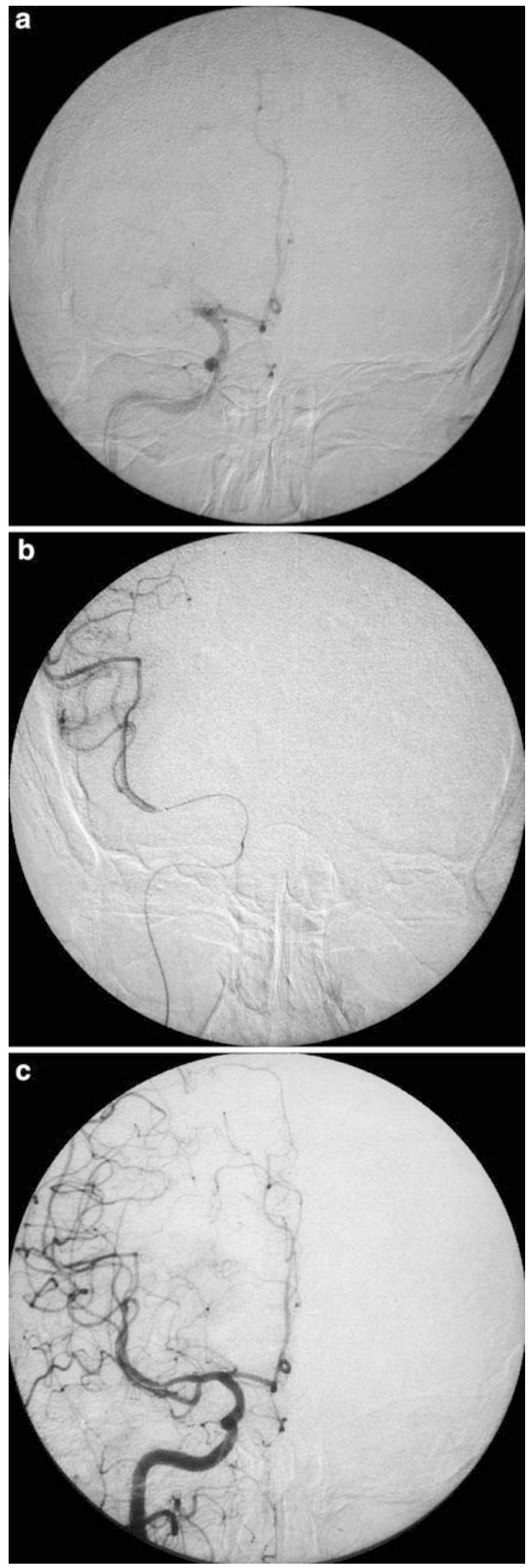

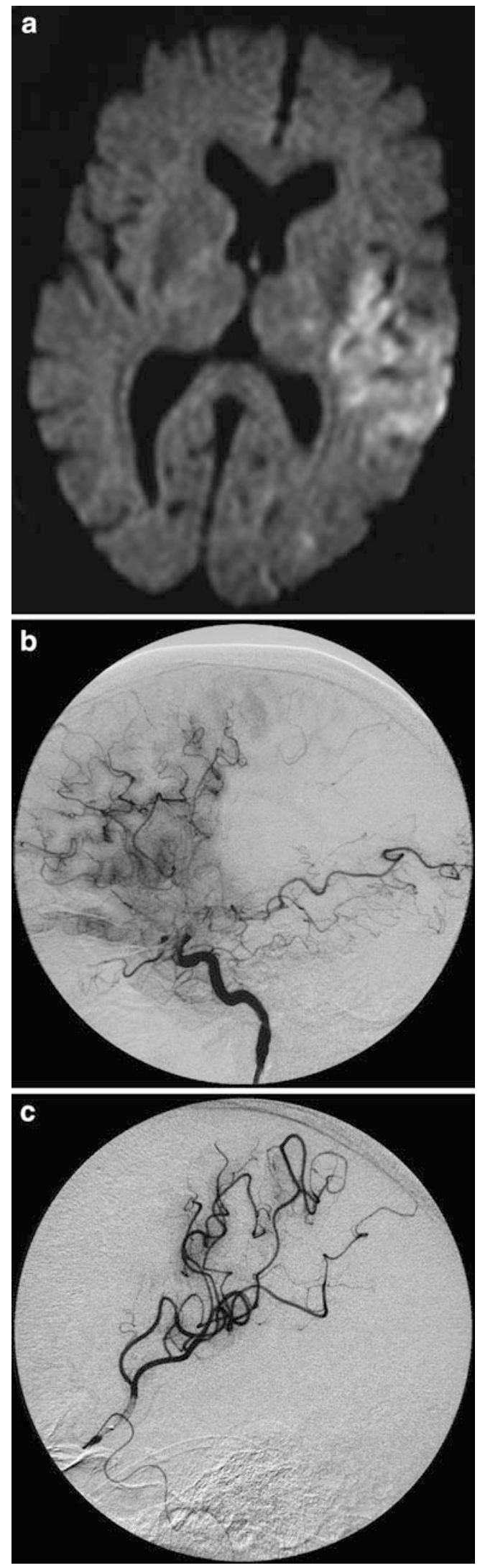

Fig. 3a-c MRI and angiography of a 57-year-old woman with acute aphasia and right-sided hemiparesis. a Diffusion-weighted MRI $(1.5 \mathrm{~T}, b=1,000)$ demonstrates infarction of the dorsal territory of the middle cerebral artery. b The late arterial phase of the angiography of the left internal carotid artery shows corresponding deficit of perfusion of the dorsal MCA branches. c The micro-catheter is navigated into the occluded branch of the MCA. Gentle contrast injection shows opacification of the nonperfused dorsal MCA area

physical aspects of micro-catheters as coolant carriers, and a model that simulates the temperature response of the brain, allowing the calculation of theoretical brain cooling rates. Most of the thermal physics and other physical aspects are dealt with in Appendices 1, 2 and 3.

\section{Heat-exchange mechanisms of the human body}

At basal metabolic rate, the human body produces approximately $80-100 \mathrm{~J} / \mathrm{s}$. In order to keep its temperature, the human body constantly exchanges heat with its surrounding environment. It has the capacity to keep its core temperature within the narrow range of $36.7^{\circ}$ $37.7^{\circ} \mathrm{C}$ in a very large ambient temperature range (Benziger [19]). The temperature of the body is regulated by neural feedback mechanisms, which operate primarily through the hypothalamus. The hypothalamus contains not only the control mechanisms, but also the key temperature sensors.

The major heat-transfer mechanisms within the human body and between the human body and its surrounding environment are radiation, conduction, convection, and evaporation of perspiration. Appendix 1 discusses these physical heat-transfer mechanisms in more detail.

A variety of responses is initiated to conserve the heat in the body and to increase heat production if the human body is exposed to a cold environment, as performed in global artificially induced hypothermia. These include vasoconstriction to decrease the flow of heat to the skin, shivering to increase heat production in the muscles, and the secretion of norepinephrine, epinephrine, and thyroxine to increase heat production. The release of epinephrine, norepinephrine and thyroxine will cause tachycardia, hypertension, and increased catabolism. Therefore, patients with a history of atrial fibrillation and congestive heart failure may not be suitable candidates for systemic hypothermia (see also [10]). For these patients local induced hypothermia would be applicable, if the method would not lower the systemic body temperature.

Micro-catheters as coolant transporters

Micro-catheters are thin, flexible, tubes that have outer diameters in the order of $1.0-2.0 \mathrm{~mm}$. Their length is in 
the order of $1.50 \mathrm{~m}$ (e.g. FasTracker; Boston Scientific). In LIT, micro-catheters are normally used to transport thrombolytic agents near to or into the blood clot. In order to be able to navigate the micro-catheter into the intracranial vessels, the tip of a so-called guiding catheter, normally with a size six or seven French (one French $=0.3 \mathrm{~mm}$ ), is first positioned in the cervical part of the vertebral or internal carotid artery. Within this guiding catheter the very thin and flexible micro-catheter can easily be moved (see Fig. 1a, b). This section will examine the physical possibility of whether the combination of guiding/micro-catheters can be used to transport coolant liquids.

Heat exchange between the endovascular micro-catheter and blood

From the femoral artery to the arch of the aorta there is a counterflow between the coolant in the micro-catheter and the blood. From the aortic arch on and in the carotid artery the coolant flows parallel to the blood. It can be proven [20] that the following relationship exists between the heat flow $\dot{Q}$, measured in joules per second, and the temperature differences $\Delta T_{\text {femoral artery }}, \Delta T_{\text {brain }}$, the average overall heat transfer coefficient $k$ and the area $A_{\mathrm{gc}}$ of the catheter:

$\dot{Q}=k A_{\mathrm{gc}} \frac{\Delta T_{\text {femoral artery }}-\Delta T_{\text {brain }}}{\ln \left(\frac{\Delta T_{\text {femoral artery }}}{\Delta \text { t }_{\text {brain }}}\right)}$

where $\Delta T_{\text {femoral artery }}$ is the difference between the femoral arterial blood temperature and the coolant temperature at the body entry point (femoral vein), and $\Delta T_{\text {brain }}$ is the difference between the arterial blood temperature in the brain and the coolant temperature in the brain. The overall heat-transfer coefficient $k$ can be computed for the given geometry. It is not in the scope of this paper to describe this constant in more detail. This paper will focus only on the experimental determination of the overall heat-transfer coefficient $k$, which is of crucial importance for answering the question of whether a micro/guiding catheter is suited to serve as a coolant transporter. In the results section of the paper measured values for $k$ will be given.

Other important physical aspects of the use of microcatheters as coolant transporters, such as the required micro-catheter input pressure and coolant fluid outflow velocity, can be found in Appendix 2. From Eq. 8 of Appendix 2 the required input pressures were calculated. Figure 4 shows the required input pressures as a function of the desired flow rates for three different micro-catheter radii. For the FasTracker-18 microcatheter we found experimental pressure values of approximately $800 \mathrm{mmHg}$ for flows $\phi_{V}$ of around $0.25 \mathrm{ml} / \mathrm{s}$. Experimentally, the tube wall of the
FasTracker-18 (Boston Scientific) micro-catheter had no visible difficulty with this high input pressure.

\section{Brain temperature-response model}

The temperature response of the brain to an endovascular applied cooling fluid can be calculated by solving the so-called bio-heat equation and is dealt with in Appendix 2. In this section, we will only apply the solution to the simplified bio-heat equation to the case were we assume that the volume of the infarcted brain tissue $\left(M_{\mathrm{IB}}\right)$ is $300 \mathrm{~g}$, which is a realistic value for an MCA occlusion. It is also assumed that the temperature of the brain $\left(T_{\mathrm{IB}, 0}\right)$ when cooling is started equals $37.0^{\circ} \mathrm{C}$. For several micro-catheter flow rates and a micro-catheter outlet coolant temperature $T_{\mathrm{mc}, \text { out }}$ of $15.0^{\circ} \mathrm{C}$ the cerebral brain temperature response was calculated. The results are displayed in Fig. 5. As intuitively expected, the larger the flow rate $\phi_{\mathrm{mc}, \text { out }}$, the faster the tissue cools down. This simple temperature model predicts that, for large values of time, the brain temperature approaches the coolant temperature.

In the case of stroke, the tissue has to be cooled down as fast as possible to mild $\left(T_{\mathrm{IB}} \approx 34^{\circ} \mathrm{C}\right)$ or moderate $\left(T_{\mathrm{IB}} \approx 28^{\circ} \mathrm{C}\right.$ ) hypothermia in order to slow down the metabolic rate, thus slowing down further acidosis, cell swelling and cell death, and widening the treatment window. According to Fig. 5, this mild-to-moderate hypothermia can be achieved within 6 min under the given circumstances.



Fig. 4 The relation between the flow rate $(\mathrm{ml} / \mathrm{min})$ and the required input pressure $(\mathrm{mmHg})$ for micro-catheters with a radius of 0.4 , 0.5 , and $0.6 \mathrm{~mm}$ 


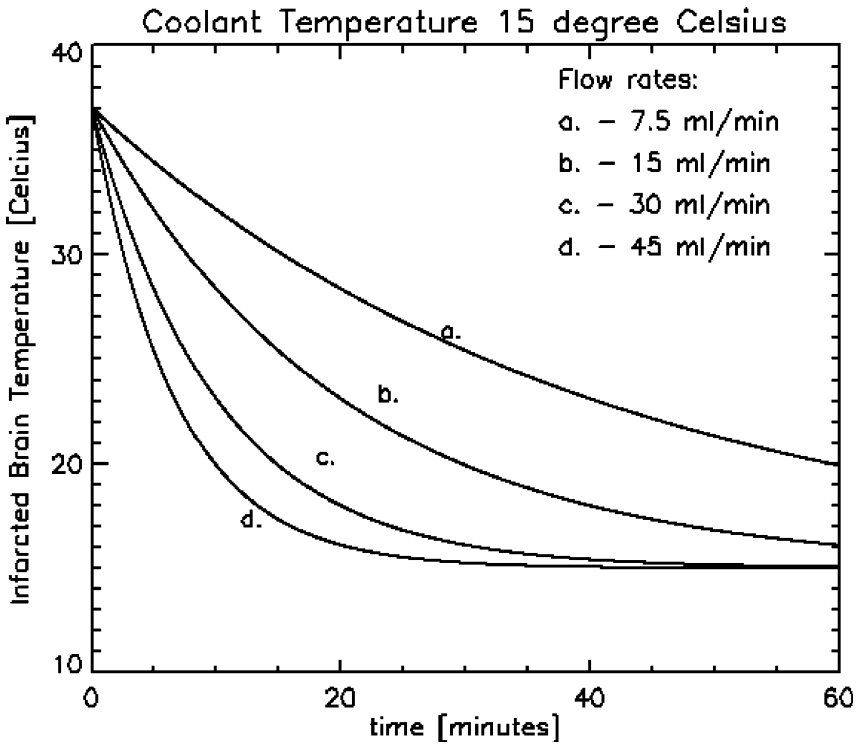

Fig. 5 Cooling curves for four different flow rates: $\phi_{\text {mc,out }}=7.5$, $15.0,30.0$, and $45 \mathrm{ml} \mathrm{min}^{-1}$. The larger the flow rate $\phi \mathrm{mc}$,out, the faster the brain cools. Coolant temperature was $15.0^{\circ} \mathrm{C}$. This simple temperature model predicts that for long periods of time, the brain temperature approaches the coolant temperature

Time to reach target hypothermia temperature

In Appendix 3 an equation is derived that relates the time necessary to reach a specific hypothermia temperature to coolant flow rate and infarcted brain mass. Figure 6 shows the time needed to reach the localized target hypothermia temperature (displayed horizontally) for an infarcted mass $M_{\mathrm{IB}}$ of $300 \mathrm{~g}$ and flow rates of 7.5 , $15.0,30.0$, and $45.0 \mathrm{ml} \mathrm{min}{ }^{-1}$. As also follows from this figure, and which is intuitively expected, the state of hypothermia is reached as quickly as possible by using as large as possible flow rates combined with as low as possible coolant temperatures.

The effect of localized hypothermia on the systemic temperature

The amount of energy $Q_{\text {cool }}$ that is extracted from the body in the case of systemic hypothermia can be computed from the following equation:

$Q_{\text {cool }}=m_{\text {body }}\left\langle C_{\text {body }}\right\rangle \Delta T$

with $m_{\text {body }}$ the mass $(\mathrm{kg}),\left\langle C_{\text {body }}\right\rangle$ the average heat capacity $\left(\mathrm{J} \mathrm{kg}^{-1} \mathrm{~K}^{-1}\right)$, and $\Delta T$ the decrease in temperature of the body. In the case of mild hypothermia $\left(\Delta T=4.0^{\circ} \mathrm{C}\right)$, the average heat capacity of the body is $3.47 \mathrm{~kJ} \mathrm{~kg}^{-1} \mathrm{~K}^{-1}$ and, assuming a body weight of $70.0 \mathrm{~kg}, Q_{\mathrm{cool}}=971.6 \mathrm{~kJ}$. According to Dixon et al. [9], the state of mild whole-body hypothermia is reached after approximately $1 \mathrm{~h}$. In the case of locally induced

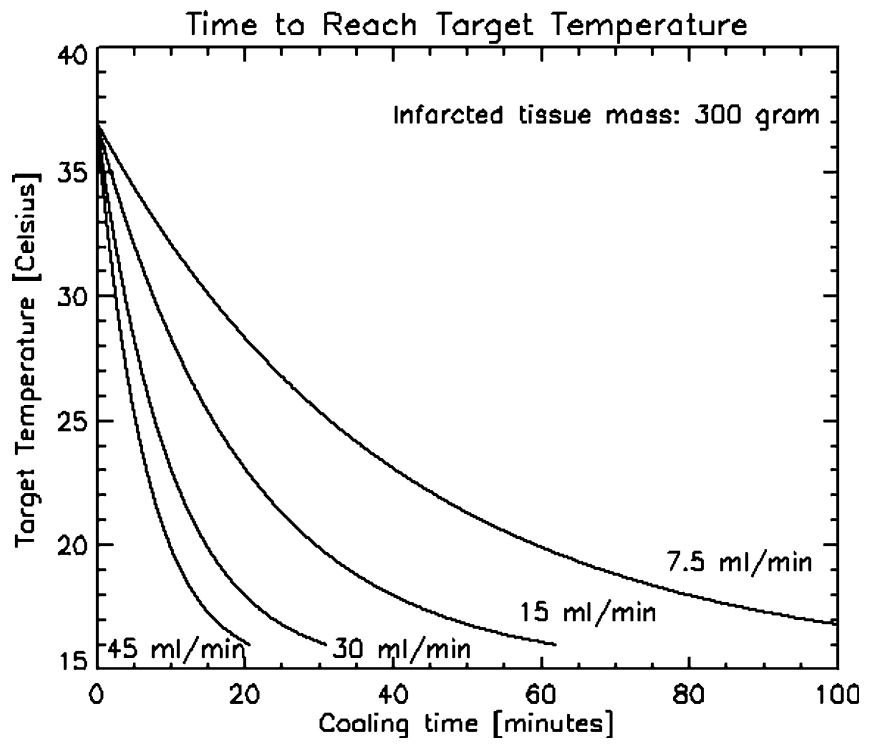

Fig. 6 The time needed to reach a specific hypothermia temperature, assuming an initial infarcted tissue temperature of $37^{\circ} \mathrm{C}$ and an infarcted tissue mass of $300 \mathrm{~g}$. The steepest curve corresponds to a micro-catheter coolant flow rate $\left(T_{\mathrm{mc}, \text { out }}=15^{\circ} \mathrm{C}\right)$ of $7.5 \mathrm{ml} \mathrm{min} \mathrm{m}^{-1}$. Also displayed are the curves for coolant flow rates of 15,30 and $45 \mathrm{ml} \mathrm{min}^{-1}$

hypothermia, a worst-case estimate of the effect of the cold saline infusion on the body temperature can be made by assuming that all extracted energy contributes to a global decrease in body temperature.

The decrease in whole-body temperature caused by a $2.0^{\circ} \mathrm{C}$ saline solution, applied at a volume rate $\phi_{\text {saline }}$ of $1,200 \mathrm{ml} / \mathrm{h}$ during $\Delta t=1.0 \mathrm{~h}$, can be approximated in the following way:

$\Delta T_{\text {body }} \approx \frac{\rho_{\text {saline }} \phi_{\text {saline }} \Delta t C_{\text {saline }} \Delta T_{\text {saline }}}{m_{\text {body }}\left\langle C_{\text {body }}\right\rangle}$

Taking $\rho_{\text {saline }}=1.024 \times 10^{3} \mathrm{~kg} \mathrm{~m}^{-3}, C_{\text {saline }}=3.93 \mathrm{~kJ} \mathrm{~kg}^{-1}$ $\mathrm{K}^{-1}, \quad \Delta T_{\text {saline }}=35^{\circ} \mathrm{C}, \quad m_{\text {body }}=70.0 \mathrm{~kg}, \quad$ and $\left\langle C_{\text {body }}\right.$ \rangle$=3.47 \mathrm{~kJ} \mathrm{~kg}^{-1} \mathrm{~K}^{-1}$ one finds a $\Delta T_{\text {body }} \approx 0.70^{\circ} \mathrm{C}$. Note that this is the maximum theoretical possible systemic decrease in body temperature; in reality the cooling will only have a local effect, due to the nearly perfect local heat exchange in the vasculature.

\section{Results}

In order to investigate experimentally the usability of micro-catheters to transport heat, we carried out several experiments that resembled the in vivo conditions as closely as possible. In the first experiment, a FasTracker-18 micro-catheter (Boston Scientific) was placed in a watercontaining basin of $37^{\circ} \mathrm{C}$. Cold water, having an inlet temperature of approximately $2^{\circ} \mathrm{C}$ (see Table 1 for exact values), was injected in the micro-catheter. Inlet and outlet temperatures were measured. 
In the second experiment, a seven French Guider Softip (Boston Scientific) guiding catheter was placed in an approximately $37^{\circ} \mathrm{C}$ basin. The micro-catheter was placed within the guiding catheter that was filled with $37^{\circ} \mathrm{C}$ water. Again, cold water, having an inlet temperature of approximately $2^{\circ} \mathrm{C}$ (see Table 1 for exact values), was injected in the micro-catheter. Inlet and outlet temperatures were also measured.

The third experiment was the same as the second experiment, but instead of a water-filled guiding catheter, an air-filled guiding catheter was used. Since air is a good thermal insulator, having a thermal conductivity coefficient in the same order of magnitude as thermal isolating plastic foam (e.g. expanded polystyrene, EPS), this experiment simulates the effect of a thick-walled, thermally insulated, guiding catheter.

Every individual experiment was repeated twice. With the aid of Eq. 4, the effective overall heat transfer coefficient was calculated and is also listed in Table 1. From the large, effective, overall heat transfer coefficient $k$ it may be concluded that a plain micro-catheter has very poor thermal insulation properties. The thermal insulation could be improved (i.e. lower $k$ value, cf. Table 1) if the guiding catheter were further insulated e.g. with plastic foam: the overall heat transfer coefficient could be lowered by a factor of approximately 2.5 3 , as demonstrated by the third experiment. Although being poor thermal insulators, the outlet temperatures of Table 1 in the second experiment, which resembles very close the in vivo situation in everyday clinical practice in interventional neuroradiology, demonstrate that a micro-catheter, placed within a blood/saline-containing guiding catheter, can serve as a coolant transporter to induce local hypothermia of infarcted areas. With special thermally insulated catheters, simulated by the third experiment, it would be possible to reach even lower brain temperatures in shorter time. Another possibility to decrease the outlet temperature of the micro-catheter is the possibility of flushing the guiding catheter slowly with cold saline solution.

\section{Discussion}

Whole-body hypothermia is reported to have numerous, unwanted, side effects [10]; these include coagulopathies $[21,22]$ that can cause severe bleeding, hypovolaemia [23, 24], arrhythmia, and infections. Although not often observed in mild hypothermia, this excludes the therapeutic application of hypothermia in patients with a history of atrial fibrillation and congestive heart failure [4, 5, 25,].

Hypotension, as well as hypertension, may occur, especially during induction of hypothermia via the skin, as a result of the release of catecholamine [26]. Also, pulmonary complications are observed, mainly related to surface cooling $[25,27]$. In addition, electrolyte abnormalities (including hypokalaemia, hyperglycaemia and metabolic acidosis) have been described [27], and intracranial pressure may increase if rewarming is done too quickly.

Induced hypothermia, with the aim of reducing the body's need for oxygen, can only be successful if the shivering reaction of the body can be suppressed. This shivering is a result of the release of catecholamine [26], which will increase, instead of decrease, the patient's demand for oxygen and glucose. The shivering reaction is reported to occur in classically induced hypothermia as well as in endovascular-induced hypothermia [9]. Shivering can be suppressed by the application of neuromuscular blocking agents such as pancuronium or vecuronium and sedatives such as diazepam and lorazepam to reduce the patient's anxiety.

The possibility of passing the site of occlusion even before the blood clot has been dissolved allows the early reperfusion of the infarcted region with nutritional solutions (e.g. oxygen, arterial blood from the femoral sheath), the application of drugs that prevent reperfusion damage (e.g. free-radical scavengers [28]), combination therapies [29], and also localized hypothermia.

It is hypothesized in this paper that locally induced hypothermia of only those parts of the body that need a

Table 1 Experimental inlet and outlet temperatures of the FasTracker-18 micro-catheter observed under different experimental conditions

\begin{tabular}{llllll}
\hline $\begin{array}{l}\text { Experiment } \\
\text { type }\end{array}$ & $\begin{array}{l}\text { Coolant flow rate } \\
\left(\mathrm{ml} \mathrm{s}^{-1}\right)\end{array}$ & $\begin{array}{l}\text { Inlet temperature } \\
\left({ }^{\circ} \mathrm{C}\right)\end{array}$ & $\begin{array}{l}\text { Outlet temperature } \\
\left({ }^{\circ} \mathrm{C}\right)\end{array}$ & $\begin{array}{l}\text { Basin temperature } \\
\left({ }^{\circ} \mathrm{C}\right)\end{array}$ & $\begin{array}{l}\text { Heat transfer coefficient } k \\
\left(\mathrm{~W} \mathrm{~m}^{-2} \mathrm{~K}^{-1}\right)\end{array}$ \\
\hline $\mathrm{A}^{\mathrm{a}}$ & 0.31 & 1.2 & 29.9 & 37.4 & 550.8 \\
$\mathrm{~A}^{\mathrm{a}}$ & 0.20 & 1.3 & 29.6 & 37.5 & 346.2 \\
$\mathrm{~B}^{\mathrm{b}}$ & 0.29 & 2.5 & 23.3 & 37.4 & 294.5 \\
$\mathrm{~B}^{\mathrm{b}}$ & 0.29 & 2.5 & 23.5 & 37.1 & 303.4 \\
$\mathrm{C}^{\mathrm{c}}$ & 0.22 & 2.0 & 15.6 & 36.5 & 126.7 \\
$\mathrm{C}^{\mathrm{c}}$ & 0.25 & 2.7 & 17.3 & 37.3 & 155.8 \\
\hline
\end{tabular}

\footnotetext{
${ }^{a}$ Micro-catheter placed directly in a warm water basin

${ }^{b}$ Micro-catheter placed in a seven French Guider Softip (Boston Scientific) guiding catheter; the guiding catheter is filled with non-moving water having the same initial temperature as the basin

${ }^{c}$ The same experiment as B, but the micro-catheter is now filled with air in order to simulate a thermal insulator. From these values, an effective heat transfer coefficient is calculated which is defined from Eq. 1
} 
slowed metabolism would achieve the same therapeutic results as systemic hypothermia, at the same time circumventing the bulk of negative side effects associated with the latter. Localized hypothermia, as described in this paper, is not a therapy that is applied on its own but always in combination with LIT or other intra-arterial catheter-based techniques. The literature about locally induced hypothermia is limited, and most of the applications described in the literature are limited to animal studies (e.g. [12] and references therein). Recently, Ding et al. [13] published data of an animal study where localized endovascular hypothermia using cold saline solution was applied to transient middle cerebral arterial occlusion, very similar to the approach described in this paper. Ding et al. [13] showed significant reductions of infarct volume, up to $90 \%$, and significantly improved motor behaviour compared with the control group. Their study supports our hypothesis that local, induced, hypothermia of the ischaemic brain, may substantially improve the clinical outcome.

From a physical point of view, the previous theoretical and experimental part showed that localized hypothermia of brain tissue jeopardized by ischaemia is, in principle, possible, with the aid of a combined guiding/ micro-catheter set-up that is used routinely in interventional neuroradiology in the treatment of acute stroke by local intra-arterial thrombolysis. The instruments and experience necessary to perform the proposed local hypothermia in stroke are available in each Department of Neuroradiology. Therefore, it is expected that the additional cost to perform the intervention will be relatively low, when compared with whole-body endovascular techniques. An advantage of locally induced hypothermia over whole-body hypothermia may be that no medication is needed to prevent the natural shivering reaction of the body to hypothermia. It is, however, uncertain whether shivering-prevention medication will be necessary in those cases where the hypothalamus is part of the locally cooled brain region, since the hypothalamus will receive normal body temperature information from the body, whereas the local sensors in the hypothalamus will record too low a local brain temperature. It is difficult to predict what the response of the hypothalamus will be to this situation. Whole-body hypothermia is frequently being carried out in combination with artificial ventilation of the patient. In the case of localized hypothermia, artificial ventilation would not be necessary in those cases where the respiratory centre of the brain in not affected by the infarction.

Another possibility, not discussed in this paper, is the induction of hypothermia just in front of the occlusion site, resulting in induction of hypothermia primarily of the penumbra and secondarily of the core of the infarction by heat conduction and heat transportation through the cortical ascending veins.
Systemic versus locally induced hypothermia

Compared with systemic hypothermia, the probability of coagulopathies is less severe in localized hypothermia since the global blood temperature is only minimally lowered. Also, the bulk of hypothermia-related dysrhythmias, including atrial fibrillation, are prevented in the case of locally induced hypothermia. This makes localized hypothermia especially attractive for patients that are also suffering from cardiac diseases.

As was shown above, another advantage of localized hypothermia over whole-body hypothermia is the fact that cooling is 30-times faster than in classic whole-body induced hypothermia via the skin using cooling blankets, etc. Compared with the newest high-tech methods, which recently became available and that induce wholebody hypothermia by cooling the blood in the inferior vena cava, the proposed locally induced hypothermia method is approximately ten-times faster for a tissue mass of $300 \mathrm{~g}$. The reason for this is that the tissue jeopardized by ischaemia is not cooled directly in the case of systemic hypothermia, since the blood vessel that feeds the infarcted region is occluded. In this type of induced hypothermia, the jeopardized tissue is cooled indirectly by thermal conduction of heat flow from the ischaemic tissue to the cooled healthy tissue. Thermal conduction is a relatively slow physical process. In the case of localized hypothermia, however, the infused coolant directly cools the ischaemic tissue. Localized hypothermia, therefore, allows a very rapid slow down of the metabolic processes, which may widen the therapeutic time window to treat the stroke-affected brain tissue.

Another issue to be mentioned in the case of wholebody hypothermia is the fact that, up till now, the temperature in the ischaemic tissue itself was never determined in all cited references. In all systemic hypothermia methods it is assumed implicitly that the temperature of the ischaemic jeopardized brain tissue will follow as rapidly as the well-perfused brain tissue. This is a doubtful assumption, since the cooling in the ischaemic part will be cooled by the slower heat conduction mechanism and not directly by the flow of cooled blood through micro-capillaries.

\section{Locally induced hypothermia and vasoconstriction}

A natural response of the blood vessel wall to tissue temperatures below $36.5^{\circ} \mathrm{C}$ is contraction (vasoconstriction). Further studies have to show whether vasoconstriction-preventing drugs have to be given immediately before and during the hypothermia therapy systematically or whether these drugs can effectively be supplied locally in low dose by the same micro-catheter that carries the coolant fluid. 
Micro-catheters and the prevention of secondary brain injury and reperfusion damage

Animal studies have shown that a combination therapy of magnesium, tirilazad and mild hypothermia is more effective [29]) than single therapies in the treatment of focal cerebral ischaemia. Also, the supplementation of antioxidants (e.g. vitamin $\mathrm{E}$, vitamin $\mathrm{C}$, and mannitol) to reduce the effects of reperfusion damage done to the vascular endothelium has been shown to have promising effects (e.g. [28]). Glutathione also seems to be an important antioxidant that might be of great importance in the prevention of reperfusion injury [30]. In principle, the proposed endovascular localized cooling method can be combined with other drug therapies. Since the microcatheter directly perfuses the ischaemic tissue, antioxidants and other drugs can effectively be administered in a low dose, directly to the tissue that requires the medication.

Factors limiting the maximum cooling rate

There are several limiting factors to the maximum obtainable cooling rate of the tissue jeopardized by ischaemia. The first is the natural flow rate of the occluded blood vessel. If the total infarcted volume $V_{\text {infarct }}$ is known from either CT or MR images, the upper flow rate could be computed from the average cerebral flow rate $\phi_{\text {cerebral }}$ whose value is approximately $46 \mathrm{ml}$ per $100 \mathrm{~g}$ brain tissue per minute. The maximum flow rate of the micro-catheter $\phi_{\mathrm{mc} \text {,max }}$ is then given by:

$\phi_{\text {mc } \text { max }}=\frac{\rho_{\text {brain }} V_{\text {infarct }}}{\phi_{\text {cerebral }}}$

in which $\rho$ brain is the density of brain tissue in kilogrammes per cubic metre. Since the coolant is administered to the body, the maximum amount of coolant per time unit that can be given to the patient will depend on the body mass and other infusions given to the patient at the same time. Another limiting factor is the maximum outflow velocity of the coolant fluid. This factor is described in Appendix 2. The next step is the development of a device that is able to pump coolant fluid through micro-catheters with an adjustable flow rate and an adjustable outlet temperature.

\section{Combination with other therapies}

In order to be able to combine the hypothermia with osmotherapy and antioxidant therapy to prevent reperfusion damage, this new device should be able to supply more than one type of fluid through the same micro-catheter. With the aid of this device, controlled and reproducible reperfusion of ischaemic tissue may be possible, allowing for the development of optimal reperfusion strategies of infarcted tissue. Besides the hypothermia, the prototype device may keep the local hypoperfusion of the ischaemic brain area upright as long as the thrombotic or thromboembolic occlusion is present. One possible solution might be to use two micro-catheters simultaneously, one carrying the thrombolytic agent close or into the occlusion, the other passing the thrombus and carrying the coolant and other medication.

\section{Conclusion}

This paper introduces the concept of local endovascular induced hypothermia using micro-catheters. In vitro measurements show that the thermal properties of a micro-catheter placed within a guiding catheter are such that they allow for rapid cooling of infarcted tissue. For a cerebral infarction having a mass of $300 \mathrm{~g}$ the proposed method cools the tissue more than 30-times faster than conventional cooling methods that operate via the skin using cooling blankets, ventilators, and rubbing the skin with a mix of water and alcohol. The proposed method would have an approximately ten-times faster cooling rate than whole-body endovascular cooling devices that cool the whole body via a cooling catheter endovascularly placed in the inferior vena cava. The proposed cooling via micro-catheters has the additional advantage that secondary brain injury preventing drugs can be administered even before the blood clot has been dissolved. The micro-catheter also allows for effective and localized supplementation of drugs that prevent vasoconstriction, normally occurring as soon as the tissue temperature sinks below $36.5^{\circ} \mathrm{C}$, allowing for acceptable perfusion rates despite hypothermia.

\section{Appendix 1}

\section{Radiation}

The body radiates electromagnetic waves. This radiated power by the human body, denoted by $P_{\text {radiation }}$, can be calculated by:

$P_{\text {radiation }}=\varepsilon \sigma S\left(T_{\text {body }}^{4}-T_{\text {ambient }}^{4}\right)$

where $\varepsilon$ is the emissivity of the human skin having a value of $0.97, \sigma$ is Boltzmann's constant $\left(5.67 \times 10^{-8} \mathrm{~W} \mathrm{~m}^{-2} \mathrm{~K}^{-4}\right), S$ is the surface of the human body (assumed to be roughly $2.0 \mathrm{~m}^{2}$ for an adult), $T_{\text {body }}$ is the skin temperature, and $T_{\text {ambient }}$ is the ambient temperature. For a skin temperature of $34.0^{\circ} \mathrm{C}$ and an ambient temperature of $23^{\circ} \mathrm{C}, P_{\text {radiation }}$ is $132.9 \mathrm{~W}$. 


\section{Conduction}

The heat transfer rate of the human body due to conduction can be calculated in the following way:

$P_{\text {conduction }}=\frac{k_{\text {air }} S\left(T_{\text {body }}-T_{\text {ambient }}\right)}{d}$

in which $k_{\text {air }}=24 \times 10^{-3} \mathrm{~W} \mathrm{~m}^{-1} \mathrm{~K}^{-1}$. The distance parameter $d$ accounts for the distance from the skin surface where the air temperature drops from $T_{\text {body }}$ to $T_{\text {ambient }}$. Assuming $d=0.045 \mathrm{~m}$ and the same ambient and skin temperature as in the radiation example, $P_{\text {conduction }}=11.7 \mathrm{~W}$.

\section{Convection}

Convection involves the transport of energy by means of the motion of the heat transfer medium. In the case of the human body this is the surrounding air. The heat losses due to convection are more difficult to calculate. Convection can be approximated using (Eq. 6) by introducing an effective heated air layer $d_{\text {eff. }}$ The stronger the air motion, the smaller the heated air layer, and the larger the energy loss due to convection. Under surgical conditions, this term is normally negligible.

\section{Perspiration}

As soon as the skin temperature reaches $37^{\circ} \mathrm{C}$, the skin will begin to sweat. Perspiration will increase rapidly with increasing skin temperature. A healthy person has a perspiration volume rate $\dot{M}$ of approximately $600 \mathrm{~g} / \mathrm{day}$, but the perspiration volume rate can be up to $1.5 \mathrm{l} / \mathrm{h}$ under extreme conditions [31]. The body is cooled by the vaporization of water. The vaporization heat $C_{\text {vap }}$ of water at body temperature is $2.436 \times 10^{3} \mathrm{~kJ} \mathrm{~kg}^{-1}$. The perspiration heat transfer rate $P_{\text {perspiration}}$, expressed in watts, of a healthy person can thus be calculated as:

$P_{\text {perspiration }}=C_{\mathrm{vap}} \dot{M}=16.9 \mathrm{~W}$

If the skin temperature drops below $37^{\circ} \mathrm{C}$, sweating will stop. A direct consequence of the physical facts presented above is that, under surgical conditions, the heat loss due to radiation alone $(132.9 \mathrm{~W})$ is larger than the basal metabolic rate $(80-100 \mathrm{~W})$, which means that the patients have to be warmed actively in order to prevent unwanted systemic hypothermia.

\section{Appendix 2}

Required micro-catheter input pressure

Since the inner radii of micro-catheters are very small, the input pressures needed to pump coolant fluid through them are very high. The relationship between the liquid volume per time unit $\phi_{\mathrm{V}}$ (flow rate) that passes through a circular tube and the required pressure difference $\Delta P$ over the tube is given by the Poiseuille-Hagen formula:

$\phi_{\mathrm{V}}=\Delta P \frac{8 \eta L}{\pi R^{4}}$

in which $\eta$ is the viscosity of the fluid transported through the micro-catheter, $L$ is the length of the microcatheter, and $R$ is the inner radius of the micro-catheter.

\section{Coolant fluid outflow velocity}

The output speed, $v_{\text {out }}$, with which the coolant leaves the micro-catheter, measured in metres per second, depends on the radius $R$ of the micro-catheter as well as on the coolant flow rate $\phi_{\mathrm{V}}$ and is given by:

$v_{\text {out }}=\frac{\phi_{\mathrm{V}}}{\pi R^{2}}$

In order to prevent damage to the blood vessel wall distal to the occlusion site, the maximum outflow velocity should not exceed a certain maximum value. Realistic outflow velocity values for micro-catheters are in the order of $1-5 \mathrm{~m} \mathrm{~s}^{-1}$. The maximum tolerable outflow velocity will depend on the ratio between the microcatheter's inner radius and the arterial inner radius. The smaller this ratio, the higher the maximum tolerable micro-catheter output velocity, as the coolant fluid jet at the micro-catheter tip will be slowed down very rapidly by the eddies that are produced in the non-moving blood behind the occlusion. To the best of the authors' knowledge, there exists no safety guideline for the maximum tolerable micro-catheter output velocity. When the technique is used clinically, before the therapeutic injection of cool saline solution is started, the position of the tip of the catheter relative to the vessel wall, as well as the size of each, has to be visualized by subtle contrast injection as shown in Figs. $2 \mathrm{~b}$ and $3 \mathrm{c}$.

\section{Appendix 3}

\section{The bio-heat equation}

For the time-dependent and spatially dependent temperature $T$ in any point of living tissue to be calculated, the bio-heat equation needs to be solved and is given by:

$\rho_{\mathrm{IB}} c_{\mathrm{IB}} \frac{\partial T}{\partial t}=\nabla\left(k_{\mathrm{IB}} \nabla T\right)-c_{\text {Blood }} W_{\text {Blood }}\left(T-T_{\text {Blood }}\right)+P$

in which $\rho_{\text {Iв }}$ is the density of the infarcted brain tissue $\left(\mathrm{kg} \mathrm{m}^{-3}\right), c_{\mathrm{IB}}$ the specific heat $\left(\mathrm{J} \mathrm{kg}^{-1} \mathrm{~K}^{-1}\right), k_{\mathrm{IB}}$ the thermal conductivity $\left(\mathrm{W} \mathrm{K}^{-1} \mathrm{~m}^{-1}\right), c_{\mathrm{Blood}}$ the specific 
heat $\left(\mathrm{J} \mathrm{kg}^{-1} \mathrm{~K}^{-1}\right)$ of blood, and $W_{\text {Blood }}$ the volumetric perfusion rate $\left(\mathrm{kg} \mathrm{m}^{-3} \mathrm{~s}^{-1}\right)$. The first term on the righthand side accounts for thermal conductivity, the second term for heat exchange of the tissue with the arterial blood and $P$ is the brain tissue's metabolic heat production. Finding solutions to the partial differential equation is far from trivial. Here we present an approximate solution by making the following assumptions. Since the blood vessel is totally occluded the volumetric perfusion rate of the blood is zero. The ischaemic brain tissue that was perfused by the artery before it became occluded is assumed to have total mass $M_{\mathrm{IB}}$. This brain tissue is during hypothermia treatment solely artificially perfused by the micro-catheter having an output flow

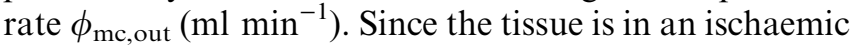
state we assume the metabolic rate $P$ to be negligible. We also assume conductive heat transport to be negligible and further assume that the heat is uniformly in space transferred via the arterioles and capillaries. Under these assumptions, Eq. 10 can be written as

$M_{\mathrm{IB}} c_{\mathrm{IB}} \frac{\mathrm{d} T_{\mathrm{IB}}}{\mathrm{d} t}=\phi_{\mathrm{mc}, \text { out }} c\left(T_{\mathrm{IB}}-T_{\text {Artery }}\right)$

This equation can be rewritten as: $\frac{\mathrm{d} T_{\mathrm{IB}}}{\mathrm{d} t}=\frac{\phi_{\mathrm{mc}, \text { out }}}{M_{\mathrm{IB}}}\left(T_{\mathrm{IB}}-T_{\mathrm{mc}, \text { out }}\right)=\kappa\left(T_{\mathrm{IB}}-T_{\mathrm{mc}, \text { out }}\right)$

with $c \approx c_{\text {Blood }}$. With $T_{\mathrm{IB}}(0)=T_{\mathrm{IB}, 0}$ and $T_{\mathrm{mc}, \text { out }}$ not time dependent, the following solution is found:

$T_{\mathrm{IB}}(t)=T_{\mathrm{IB}, 0}+(\exp (-\kappa t)-1)\left(T_{\mathrm{IB}, 0}-T_{\mathrm{mc}, \text { out }}\right)$

Time to reach target hypothermia temperature

Of more practical use than Eq. 13 is an expression that relates to the time necessary to reach a specific hypothermia temperature $T_{\text {hypothermia }}$, while given the mass of the tissue jeopardized by ischaemia, the coolant temperature, and the coolant flow rate. It can be proven that the time $t$ needed to reach a target temperature of $T_{\text {hypothermia }}$ (with the additional condition that $\left.T_{\text {mc,out }}<T_{\text {hypothermia }}<T_{\mathrm{IB}}\right)$ is given by:

$t\left(T_{\text {hypothermia }}\right)=-\frac{M_{\mathrm{IB}}}{\phi_{\mathrm{mc}, \text { out }}} \ln \left(\frac{T_{\text {hypothermia }}-T_{\mathrm{IB}}(0)}{T_{\mathrm{IB}}(0)-T_{\mathrm{mc}, \text { out }}}+1\right)$

\section{References}

1. Walpoth B, Walpoth-Aslan B, Mattle H, Radanov B, Schroth G, Schaeffler L, Fisher A, Segesser L, Althaus U (1997) Outcome of survivors of accidental deep hypothermia and circulatory arrest treated with extracorporal blood warming. N Engl J Med 337:1500-1505

2. Dietrich WD, Busto R, Halley M, Valdes I (1990) The importance of brain temperature in alterations of the blood-brain barrier following cerebral ischemia. J Neuropathol Exp Neurol 49:486-497

3. Schwab S, Schwarz S, Spranger M, Keller E, Bertram M, Hacke W (1998) Moderate hypothermia in the treatment of patients with severe middle cerebral artery infarction. Stroke 29:2461-2466

4. Maher J, Hachinski V (1993) Hypothermia as a potential treatment for cerebral ischemia. Cerebrovasc Brain Metab Rev 5:277-300

5. Ginsberg MD, Sternau LL, Globus YT, Dietrich WD, Busto R (1992) Therapeutic modulation of brain temperature: relevance to ischemic brain injury. Cerebrovasc Brain Metab Rev 4:189-225
6. Krieger DW, DeGeorgia MA, Abou-Chebl A, Andrefsky JC, Sila CA, Katzan IL, Mayberg MR, Furlan AJ (2001) Cooling for acute ischemic brain damage (COOL AID): an open pilot study of induced hypothermia in acute ischemic stroke. Stroke 32:1847-1854

7. Gillooly JF, Brown JH, West GB, Savage VM, Charnov EL (2001) Effects of size and temperature on metabolic rate. Science 293:2248-2251

8. Ganong WF (1995) Review of medical physiology, textbook. Prentice-Hall International, p 258

9. Dixon SR, Whitbourn RJ, Dae MW, Grube E, Sherman W, Schaer GL, Jenkins JS, Baim DS, Gibbons RJ, Kuntz RE, Popma JJ, Nguyen TT, O'Neill WW (2002) Induction of mild hypothermia with endovascular cooling during primary percutaneous coronary intervention for acute myocardial infarction. J Am Coll Cardiol 40:1928-1934

10. Hammer M, Krieger DW (2002) Acute ischemic stroke: is there a role for hypothermia? Cleve Clin J Med 69:770-785
11. Wang H, Olivero W, Lanzino G, Elkins W, Rose J, Honings D, Rodde M, Burnham J, Wang D (2004) Rapid and selective cerebral hypothermia achieved using a cooling helmet. J Neurosurg 100:272-277

12. Noguchi Y, Nishio S, Kawauchi M, Asari S, Ohmoto T (2002) A new method of inducing selective brain hypothermia with saline perfusion into subdural space: effects on transient cerebral ischemia in cats. Acta Med Okayama 56:279-286

13. Ding Y, Li J, Luan X, Lai Q, McAllister JP II, Phillis JW, Clark JC, Guthikonda M, Diaz FG. (2004) Local saline infusion into ischemic territory induces regional brain cooling and neuroprotection in rats with transient middle cerebral artery occlusion. Neurosurgery 54:956-964, discussion 964-965 
14. Furlan A, Higashida R, Wechsler L, Gent W, Rowley H, Kase C, Pessin M, Ahuja A, Callahan F, Clark M, Silver F, Rivera F (1999) Intra-arterial prourokinase for acute ischemic stroke. The PROACT II study: a randomised controlled trial. Prolyse in acute cerebral thromboembolism. JAMA 282:20032011

15. Gönner F, Remonda L, Mattle H, Sturzenegger M, Ozdoba C, Lövblad KO, Baumgartner R, Bassetti C, Schroth $G$ (1998) Local intra-arterial thrombolysis in acute ischemic stroke. Stroke 29:1894-1900

16. Arnold M, Schroth G, Nedeltchev K, Loher T, Remonda L, Stepper F, Sturzenegger M, Mattle HP (2002) Intraarterial thrombolysis in 100 patients with acute stroke due to middle cerebral artery occlusion. Stroke 33:1828-1833

17. Arnold M, Nedeltchev K, Schroth G, Baumgartner R, Remonda L, Loher T, Stepper F, Sturzenegger M, Schuknecht B, Mattle HP (2004) Clinical and radiological predictors of recanalisation and outcome of 40 patients with acute basilar artery occlusion treated with intra-arterial thrombolysis (editorial commentary p 811). J Neurol Neurosurg Psychiatry 75:857-862
18. Schroth G, Berlis A, Mayer T, Remonda L, Brekenfeld C, Ozdoba C, Wiest R, Slotboom J (2003) Interventionelle Neuroradiologische Techniken zur frühen Behandlung des Schlaganfalles. Therapeutische Umschau 60:569583

19. Benziger TH (1969) Heat regulation homeostasis of central temperature in man. Physiol Rev 49:671

20. Lienhard IV JH, Lienhard V JH (2003) A heat transfer textbook, 3rd edn. Phlogiston, Cambridge

21. Watts DD, Trask A, Socken K, Perdue P, Dols S, Kaufmann C (1998) Hypothermia coagulopathy in trauma: effect of varying level of hypothermia on enzyme speed, platelet function and fibrinolytic activity. J Trauma 44:846-854

22. Patt A, McCroskey BL, Moore EE (1988) Hypothermia induced coagulopathies in trauma. Surg Clin North Am 68:775-785

23. Reuler JB (1978) Hypothermia: pathophysiology, clinical settings, and management. Ann Intern Med 89:519-527

24. Granberg PO (1991) Human physiology under cold exposure. Arctic Med Res 50:23-27

25. Clifton GL, Allen S, Barrodale P, Plenger P, Berry J, Koch S, Fletcher J, RL Hayes, Choi SC (1993) A phase II study of moderate hypothermia in severe brain injury. $\mathbf{J}$ Neurotrauma 10:263-271
26. Goldstein D, Frank SM (2001) The wisdom of the body revisited: the adrenomedullary response to mild core hypothermia in humans. Endocr Regul 35:3-7

27. Marion DW, Penrod LE, Kelsery SF, Obrist WD, Kochanek PM, Palmer AM, Wisniewski SR, DeKosky ST (1997) Treatment of traumatic brain injury with moderate hypothermia. $\mathrm{N}$ Engl J Med 336:540-546

28. Gunel E, Caglayan F, Caglayan O, Dilsiz A, Duman S, Aktan M (1998) Treatment of intestinal reperfusion injuries using antioxidant agents. J Pediatr Surg 33:1536-1539

29. Zausinger S, Westermaier T, Plesnila N, Steiger HJ, Schmid-Elsaesser R (2003) Neuroprotection in transient focal cerebral ischemia by combination drug therapy and mild hypothermia. Stroke 34:1526-1532

30. Hastie LE, Patton WF, Hechtman HB, Shepro D (1997) Filamin redistribution in an endothelial cell reoxygenation injury model. Free Radic Biol Med 22:955-966

31. Guyton AC (1971) Basic human physiology: normal function and mechanisms of disease. Saunders 